\title{
Hélène Pagezy et la faim de viande
}

Hélène Pagezy and the hunger for meat

\section{Igor de Garine}

\section{CpenEdition}

Journals

Édition électronique

URL : http://journals.openedition.org/ethnoecologie/1422

DOI : 10.4000/ethnoecologie.1422

ISSN : 2267-2419

\section{Éditeur}

Laboratoire Eco-anthropologie et Ethnobiologie

\section{Référence électronique}

Igor de Garine, « Hélène Pagezy et la faim de viande », Revue d'ethnoécologie [En ligne], 3 | 2013, mis en ligne le 12 novembre 2013, consulté le 03 mai 2019. URL : http://journals.openedition.org/ ethnoecologie/1422; DOI : 10.4000/ethnoecologie.1422

Ce document a été généré automatiquement le 3 mai 2019.

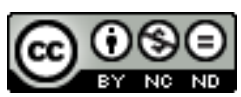

Revue d'ethnoécologie est mis à disposition selon les termes de la licence Creative Commons Attribution - Pas d'Utilisation Commerciale - Pas de Modification 4.0 International. 


\title{
Hélène Pagezy et la faim de viande
}

\author{
Hélène Pagezy and the hunger for meat
}

\author{
Igor de Garine
}

1 Une des préoccupations majeures de notre époque est la relation de la culture avec la physiologie. Comment un phénomène qui relève de la culture peut-il influencer directement la physiologie?

2 On a envisagé (Jenner et al. 1987) la relation qui existe entre le stress d'origine culturelle et la sécrétion decatécholamines dans l'organisme mais cette sécrétion indique simplement qu'il est en éveil face à une stimulation culturelle - pas nécessairement perçue comme négative.

3 Chez les populations de la forêt africaine telles les Twa et les Oto étudiées par H. Pagezy, on observe que pendant la période de soudure alimentaire, les individus ont une perception négative de leur régime. À cette période, ils ne compensent pas leur aliment de base très valorisé : la viande.

4 Les membres de cette communauté considèrent qu'ils endurent un stress nutritionnel. L'enquête nutritionnelle quantitative montre que le régime de la période difficile est équivalent nutritionnellement au régime normal dans lequel la viande est l'aliment de base. On note pourtant une diminution du poids (en particulier celui des enfants) durant la période considérée comme difficile. C'est donc la perception culturelle qu'ils ont de leur régime qui influe sur le statut nutritionnel des individus.

5 Il s'agit ici d'une contribution importante apportée par Hélène Pagezy à l'Anthropologie de l'Alimentation (Garine \& Pagezy 1989 ; Pagezy 1982, 2004). 


\section{BIBLIOGRAPHIE}

Garine I. de \& Pagezy H. 1989 - Faim saisonnière et « faim de viande ». In Se nourrir en forêt équatoriale: Anthropologie alimentaire des populations des régions forestières humides d'Afrique. Paris, Unesco/MAB : 43

Jenner D.A., Harrison G.A., Prior I.A.M., Leonetti D.L. \& Fujumoto M. 1987 - Interpopulation comparisons of catecholamine excretion. Annals of Human Biology $14: 1-9$

Pagezy H. 1982 - Seasonal hunger as experienced by the oto and the twa of a Ntomba village in the equatorial forest (lake Tumba, Zaïre). Ecol. food and Nutr. 12 139-153.

Pagezy H. 2004 - Gibiers, poissons ou chenilles ? Comment les Ntomba du Congo (ex Zaïre) satisfont-ils en toute saison leurs besoins en protéines et leurs normes culturelles. In Aubaile F., Bernard M., Pasquet P. (Ed.), La viande, un aliment, des symboles. Edisud, Collection Écologie Humaine : 191-204. 